\title{
Isolated ectopia lentis
}

INSERM

\section{Source}

INSERM. (1999). Orphanet: an online rare disease and orphan drug data base. Isolated ectopia lentis. ORPHA:1885

Isolated ectopia lentis (IEL) is a rare, clinically variable, eye disorder characterized by dislocation of the lens, often causing significant reduction in visual acuity. 